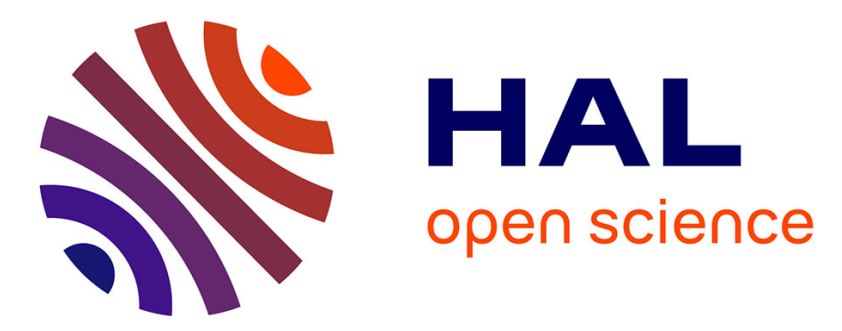

\title{
Low frequency Raman scattering from surface vibrational modes and size of microheterogenities in an amorphous matrix
}

\author{
K. Lipinska-Kalita, G. Mariotto, A. Fontana
}

\section{- To cite this version:}

K. Lipinska-Kalita, G. Mariotto, A. Fontana. Low frequency Raman scattering from surface vibrational modes and size of microheterogenities in an amorphous matrix. Journal de Physique IV Proceedings, 1994, 04 (C4), pp.C4-469-C4-472. 10.1051/jp4:19944112 . jpa-00252562

HAL Id: jpa-00252562

https://hal.science/jpa-00252562

Submitted on 1 Jan 1994

HAL is a multi-disciplinary open access archive for the deposit and dissemination of scientific research documents, whether they are published or not. The documents may come from teaching and research institutions in France or abroad, or from public or private research centers.
L'archive ouverte pluridisciplinaire HAL, est destinée au dépôt et à la diffusion de documents scientifiques de niveau recherche, publiés ou non, émanant des établissements d'enseignement et de recherche français ou étrangers, des laboratoires publics ou privés. 


\title{
Low frequency Raman scattering from surface vibrational modes and size of microheterogenities in an amorphous matrix
}

\author{
K.E. LIPINSKA-KALITA ${ }^{(1)}$, G. MARIOTTO and A. FONTANA \\ Department of Physics, University of Trento, Via Sommarive 14, 38050 Povo (Trento), Italy
}

\begin{abstract}
Polarized room-temperature Raman scattering spectra measured on heat-treated $\mathrm{GeO}_{2}$-based glasses show features resembling particle peaks. They are related to the discrete particle-like structure of thermally treated samples. We have also found that our light scattering spectra have characteristic polarization properties.
\end{abstract}

\section{1. - Introduction}

Our previous studies have proved that Raman spectroscopy is a useful tool in the study of oxide glasses and of their early stages of crystallization [1-3]. In particular, low frequency Raman scattering (below $200 \mathrm{~cm}^{-1}$ ) is sensitive to structural features with characteristic lengths from one to tens of nanometers, i.e. at intermediate scale between the molecular and bulk regimes. Glasses exhibit density fluctuations over this range, and as a consequence, their Raman spectra display features not observed for ordered crystals. On the other hand, the early stages of nucleation in glasses occur in the same length scale. With regard to the light-scattering processes in these systems, the spectral region between the Brillouin scattering and the optical phonon scattering consists of a broad band over which one or more maxima are imposed. These are noted as the boson and the particle peak [4], respectively.

In the work which is presented here we are mainly interested in the particle peak, which is directly associated with the mechanical resonances of microheterogenities (particles, microcrystals or aggregates) in an amorphous matrix [5-7]. It is due to confined acoustic phonon modes in a small spherical volume.

(1) On leave from Jagellonian University, Krakow, Poland 


\section{2. - Experimental}

The host glass was $\mathrm{GeO}_{2}$ containing $\mathrm{Ga}_{2} \mathrm{O}_{3}$ and $\mathrm{K}_{2} \mathrm{O}$ (molar ratios $80 \%$, $15 \%$, and $5 \%$ ). The reason for mixing $\mathrm{K}_{2} \mathrm{O}$ was to lower the melting and heat treatment temperatures. Glass with a high optical quality was prepared by melting in a $\mathrm{Pt}$ crucible proper amounts of high purity oxides, and by rapid quenching in air. In order to study the very early steps of nucleation and to control the size of the microcrystals we performed thermal treatments much below the crystallization temperature, determined by differential thermal method to be $900{ }^{\circ} \mathrm{C}(10 \mathrm{~K} / \mathrm{min})$. During the experiments the samples in form of small rods $(20 \times 1 \mathrm{~mm})$ were mounted in an evacuated cryostat.

Room-temperature Raman scattering measurements were carried out using the $488.0 \mathrm{~nm}$ line of an $\mathrm{Ar}^{+}$-ion laser operating at $300 \mathrm{~mW}$. The $90^{\circ}$ scattered light was analyzed by a Jobin-Yvon double-monochromator (Ramanor, mod. HG2-S, with holographic gratings, 2000 lines/mm) and detected by a cooled photon-counting system, interfaced to a multichannel analyser.

Both anti-Stokes and Stokes Raman spectra were recorded at data intervals between $0.5 \mathrm{~cm}^{-1}$ and $1 \mathrm{~cm}^{-1}$. To investigate the polarization features of the Raman scattering we carried out the measurements in the VV as well as in HV polarization.

Finally, scanning electron microscope (SEM) pictures were obtained by using a commercial equipment (JEOL, mod. JSM-6300).

\section{3. - Results and discussion}

Besides the boson band, Raman spectra of heat treated samples, obtained with VV polarization, exhibit distinct Stokes and anti-Stokes peaks, close to the laser line (Fig. 1 A, B, C, D). Our spectra show that the increase of heat treatment time or temperature causes a substantial difference in the scattering behaviour. In fact, the observed peaks are systematically shifting to the lower frequency side and growing in intensity when the duration or the temperature of treatment increase. In the spectrum of the glass after the first heat treatment (Fig. 2 A), the particle-like peak in the tail of the Rayleigh line is much broader and less well defined than in the spectra of samples which underwent longer or higher-temperature treatments (Fig. 2 B, C, D). This behaviour makes it clear that the size distribution of particles or microheterogenities in that material is rather broad. These particle-like peaks were not observed in the depolarized (HV) spectra. The depolarization ratios $\left(\rho=\mathrm{I}_{\mathrm{HV}} / \mathrm{I}_{\mathrm{VV}}\right)$ confirm that the host matrix remain completely glassy for samples after the first three steps of heat treatment. In contrast, the depolarization ratio $\rho$ for the sample annealed at $750{ }^{\circ} \mathrm{C}$ during 5 hours indicates that the host matrix is nearly almost crystalline. 


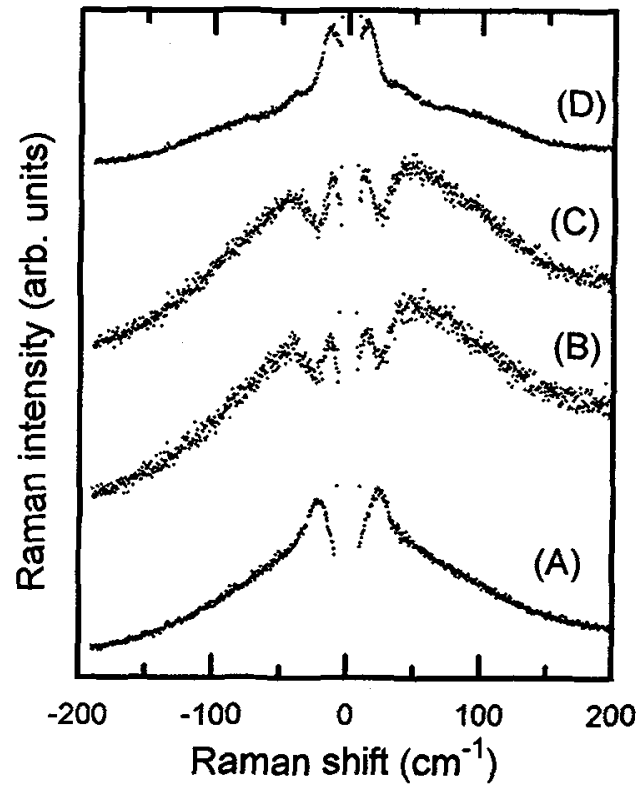

Fig. 1: Room- temperature Stokes and anti-Stokes Raman spectra of glass samples after heat treatment:
(A) $650^{\circ} \mathrm{C}, 5 \mathrm{~h}$;
(B) $650^{\circ} \mathrm{C}$, $5 \mathrm{~h}$ and $700^{\circ} \mathrm{C}$, $5 \mathrm{~h}$;
(C) $650^{\circ} \mathrm{C}$, $5 \mathrm{~h}$ and $700^{\circ} \mathrm{C}, 10 \mathrm{~h}$;
(D) $750^{\circ} \mathrm{C}, 5 \mathrm{~h}$.

We assigned the very low-frequency polarized peaks to localized acoustic phonon modes (i.e. surface vibrational modes) of small spheroidal particles which grew during the thermal annealing and separated from the glassy phase $[4,7]$.

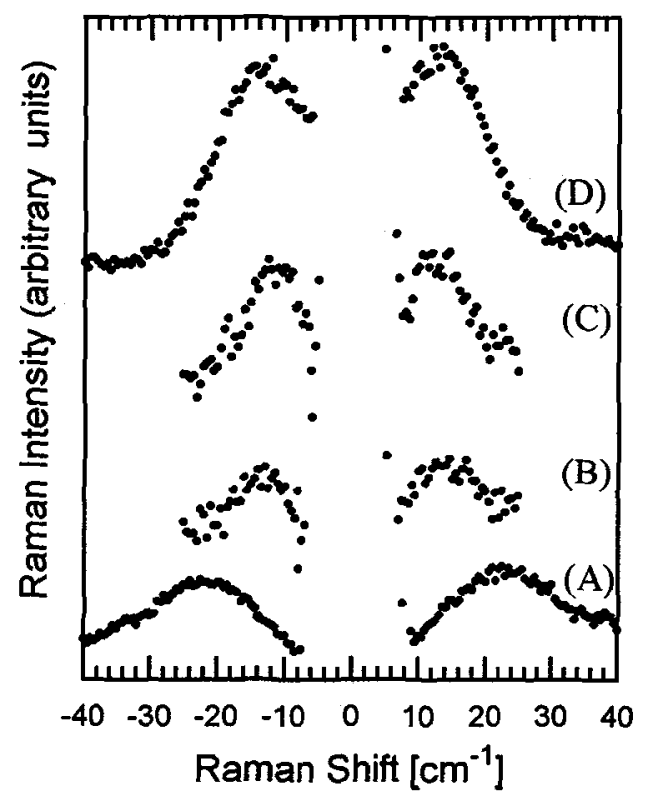

Fig. 2: Very low-frequency roomtemperature Stokes and anti-Stokes Raman spectra of glass samples after heat treatment:
(A) $650^{\circ} \mathrm{C}, 5 \mathrm{~h}$;
(B) $650^{\circ} \mathrm{C}$, $5 \mathrm{~h}$ and $700^{\circ} \mathrm{C}, 5 \mathrm{~h}$;
(C) $650^{\circ} \mathrm{C}$, $5 \mathrm{~h}$ and $700^{\circ} \mathrm{C}, 10 \mathrm{~h}$;
(D) $750^{\circ} \mathrm{C}, 5 \mathrm{~h}$. 
Under these assumptions there is a direct relationship between the peak-frequency and the size of particles $[5,6]$ :

$$
\omega=0.8 \mathrm{v} / 2 \mathrm{ac},
$$

where $\omega$ is the peak wavenumber, $v$ is the sound speed, $c$ is the speed of light in vacuum and $2 \mathrm{a}$ is the particle diameter. If we substitute in the above formula the sound speed appropriate to microcrystals $\left(6 \times 10^{3} \mathrm{~ms}^{-1}\right)$, which is close to the sound speed in amorphous germanium oxide [8], we can calculate that the diameter of our particles is changing from $80 \AA$ at $650^{\circ} \mathrm{C}$ to $140 \AA$ at $750^{\circ} \mathrm{C}$, corresponding to a particle peak shift from $22 \mathrm{~cm}^{-1}$ to $12 \mathrm{~cm}^{-1}$ (Fig. $2 \mathrm{~A}-\mathrm{D}$ ).

SEM images show a well-resolved granularity at a scale below $100 \mathrm{~nm}$ (i.e. the presence of particle-like small structures) in all our heat-treated samples. These microheterogenities were in fact considered particles for the purposes of our analysis. However, the estimation of the exact size of particles on the basis of SEM images proved to be difficult owing to the lack of resolution in this size scale.

\section{4. - Conclusions}

It appears that low-frequency Raman scattering is a useful probe of glass structure at the length scale up to about $20 \mathrm{~nm}$. In particular, Raman spectroscopy constitutes a very convenient diagnostic technique for studying the vibrational dynamics of microheterogenities in amorphous matrices. This is a simple, non-destructive method, and in our case may be complementary to other analytical techniques such as transmission electron microscopy, small angle $\mathrm{X}$-ray and neutron scattering, etc..

\section{References}

[1] K.E. Lipinska-Kalita and G. Mariotto, J. Non-Cyst. Solids 128 (1991) 285.

[2] K.E. Lipinska-Kalita and G. Mariotto, J. Mol. Structure 267 (1992) 241.

[3] K.E. Lipinska-Kalita and G. Mariotto, Proc. XIII Intern. Conf. on Raman Spectroscopy, Eds. W. Kiefer et al. (J. Wiley \& Sons, Chichester, 1992) p. 1000.

[4] E. Duval, A. Boukenter and B. Champagnon, Phys. Rev. Lett. 56 (1986) 56.

[5] H. Lamb, Proc. London Math. Soc. 13 (1892) 187.

[6] A. Tamura and T. Ichinokawa, J. Phys. C 16 (1983) 4779.

[7] A. Tanaka, S. Onari and T. Arai, Phys. Rev. B 47 (1993) 3.

[8] N.N. Ovsyuk, E.B. Gorokhov, V.V. Grishchenko and A.P. Shebanin, JEPT Lett. 47 (1988) 298. 